Pengembangan Rekayasa dan Teknologi, Vol 16, No. 1, Juni 2020, pp 1-8

p-ISSN: 1410-9840 \& e-ISSN: 2580-8850

http://journals.usm.ac.id/index.php/jprt/index

\title{
NODEMCU DAN KONTROL PENGUKURAN PH AIR BERBASIS ANDROID UNTUK MENENTUKAN TINGKAT KEJERNIHAN PADA AIR TAWAR
}

\author{
Febrian Wahyu Christanto ${ }^{1}$, Susanto ${ }^{2}$, Basworo Ardi Pramono ${ }^{3}$, Ilham Ardiyanto ${ }^{4}$, \\ Retomika Ryan Hidayatulloh ${ }^{5}$ \\ Jurusan Teknologi Informasi, Universitas Semarang, Indonesia

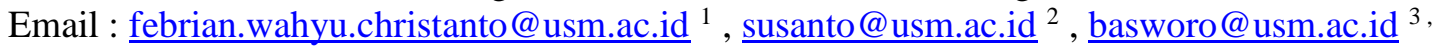 \\ $\underline{\text { ilhamardi732@gmail.com }}^{4}$, hidayatulloh25@ gmail.com $^{5}$
}

\begin{abstract}
Water is the environment for the development of living things. At present, many people use water for businesses. Businesses on it such as water refill businesses, fish cultivation either as consumption or as ornamental fish, and so on. There is a lot to consider in water terms like temperature changes, water pH balance, and cleanliness especially for fish farming businesses, so that the fish can survive and thrive. With these problems, then designed a water $\mathrm{pH}$ control device to monitor the level of fresh water clarity. This water $\mathrm{pH}$ controller will automatically balance the $\mathrm{pH}$ that is not suitable then quickly make changes by being controlled by NodeMCU. The pH sensor is used as a measurement of acidity or basicity of a solution for system measurement and control purposes. The purpose of making this tool is expected to be able to assist in daily life by facilitating community businesses related to clear water, so that what is done by users in terms of maintaining the level of fresh water clarity becomes more practical, economical, and efficient. With this tool, it can reduce the concern of unstable water pH and water temperature until 57\%, especially for businessmen and fish farmers.
\end{abstract}

Keyword : Acid-base content; NodeMCU; pH sensor; Temperature sensor

\section{PENDAHULUAN}

Air adalah sumber daya alam yang sangat penting bagi makhluk hidup, manfaatnya sangat banyak bagi manusia, hewan, dan tumbuhan. Apalagi Air sebagai konsumsi manusia dan lingkungan hidup ikan harus mampu mendukung kehidupan dan pertumbuhan ikan tersebut. Terutama pada ikan seperti ikan hias dan ikan budidaya selalu terjadi perubahan akibat perubahan suhu yang mendadak, ini dapat menyebabkan ikan mengalami stres bahkan perubahan suhu bisa mengakibatkan ikan akan mati [1].

Ada bermacam-macam jenis ikan terutama jenis ikan hias di dunia ini. Namun secara kesimpulan macam-macam jenis ikan hias dibagi menjadi dua, yaitu jenis ikan hias air tawar dan ikan hias air laut. Cara pemeliharaannya pun bermacam-macam, ada yang mudah dan ada pula yang sulit, ada yang dipelihara di akuarium, dan ada pula yang dipelihara di kolam. Memelihara ikan hias ini ternyata juga banyak manfaat yan g tersembunyi antara lain adalah menyehatkan jantung, mengurangi stress, sebagai terapi beberapa bentuk penyakit, menurunkan tekanan darah, untuk anak austistik, dan masih banyak lagi manfaat lainnya [2].

Dalam hal ini kemajuan teknologi sangat berkembang pesat dalam pembuatan alat-alat yang canggih, yaitu alat yang dapat bekerja secara otomatis dan memiliki ketelitian tinggi sehingga dapat mempermudah pekerjaan yang dilakukan oleh pengguna menjadi lebih praktis, ekonomis, dan efisien. Perkembangan teknologi tersebut telah mendorong kehidupan manusia untuk hal- hal yang serba otomatis. Maka dari itu yang awalnya menggunakan serba manual sekarang beralih ke otomatis. Tidak terkecuali dengan proses pemeliharaan ikan hias yang menggunakan alat bantu untuk kemudahan dalam pemeliharaannya. Untuk proses pemeliharaan ikan hias harus diperhatikan nilai kadar keasaman air pada akuarium. Selama ini proses pengontrolan dan pengukuran $\mathrm{pH}$ air pada ikan hias di akuarium masih dilakukan secara manual, misal mengukur $\mathrm{pH}$ air dengan menggunakan $\mathrm{pH}$ meter digital dan kemudian apabila nilai $\mathrm{pH}$ diluar batas toleransi yaitu antara $\mathrm{pH}$ 6,0 - pH 9,0 diperlukan suatu usaha yang cepat untuk menetralkan kembali $\mathrm{pH}$ air tersebut [3]. Sedangkan budidaya ikan akan berhasil dengan baik dan pertumbuhan ikan menjadi lebih optimal apabila kondisi $\mathrm{pH}$ air tawar terjadi pada kisaran $\mathrm{pH} 7,0-\mathrm{pH}$ 8,5 meter digital yang sudah modern, tetapi masih mempunyai kekurangan, yaitu perubahan yang lambat yang merupakan masalah penting dalam menentukan skala yang valid. Maka dari itu penelitian ini akan menggunakan NodeMCU untuk pengukuran $\mathrm{pH}$ dan aplikasi kontrol berbasis Android ini diharapkan akan menghasilkan suatu sistem yang lebih baik daqlam hal menjaga tingkat kejernihan air tawar. 
Pengembangan Rekayasa dan Teknologi, Vol 16, No. 1, Juni 2020, pp 1-8

p-ISSN: 1410-9840 \& e-ISSN: 2580-8850

http://journals.usm.ac.id/index.php/iprt/index

\section{METODE}

\subsection{Metode Pengembangan Sistem}

Dalam perancangan sistem diperlukan caracara untuk mengembangkan sistem dengan yang diharapkan. Metode ini adalah metode Prototype. Model Prototype dapat gunakan untuk menyambungkan ketidakpahaman pengguna mengenai hal teknis dan memperjelas spesifikasi kebutuhan yang diinginkan pengguna kepada pengembang perangkat lunak. Model Prototype dimulai mengumpulkan kebutuhan pelanggan terhadap perangkat lunak yang akan dibuat. Lalu dibuatlah program Prototype agar pengguna lebih terbayang dengan apa yang sebenarnya diinginkan.

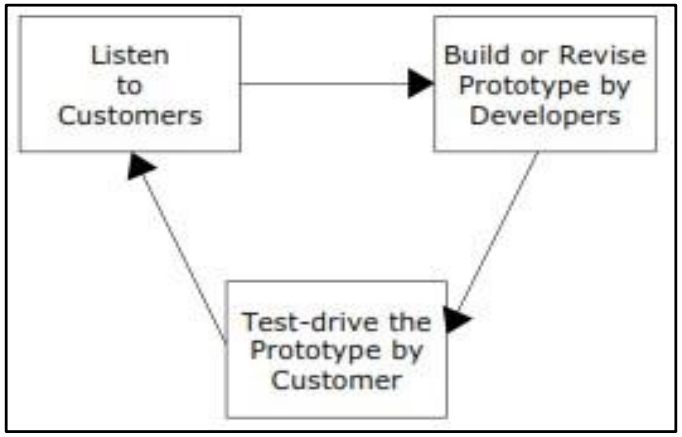

Gambar 1. Model Prototype [4]

Adapun penjelasan mengenai tahap-tahap dalam pemodelan Prototype pada Gambar 1 adalah sebagai berikut :

1. Komunikasi, pada tahap ini, penulis melakukan komunikasi dengan cara mewawancarai beberapa pengguna dan pengusaha ikan hias agar mendapatkan informasi tentang penggunaan dan pemakaian air. Dengan begitu peneliti bisa mengumpulkan data dan informasi yang diperlukan untuk membuat laporan ini.

2. Pembentukan prototype, peneliti mulai membuat perangkat prototype pengontrolan $\mathrm{pH}$ air sesuai dengan rancangan desain dan sketsa prototype yang sudah dibuat dan direncanakan sebelumnya.

3. Penyerahan sistem, penulis mempublikasikan hasil penelitian dan mengujikan perangkat prototype pengontrolan $\mathrm{pH}$ air bersama pengusaha ikan hias untuk selanjutnya dilakukan evaluasi-evaluasi pada perangkat prototype yang sudah dibuat sebelumnya.

\subsection{Kerangka Pemikiran}

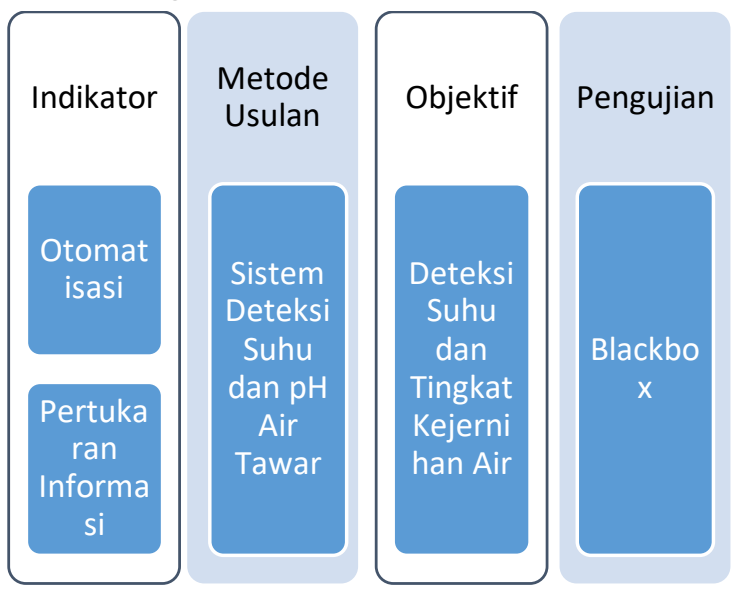

Gambar 2. Kerangka Pemikiran

Penelitian ini memiliki dua (2) indikator yang menentukan arah dari penelitian. Indikator penelitian ini Otomatisasi dan Pertukaran Informasi perangkat IoT dengan NodeMCU yang dibangun. Sehingga untuk mencapai permasalahan ini diusulkanlah sebuah sistem deteksi otomatis suhu dan kelembaban jamur tiram. Objektif dari penelitian ini adalah pengambilan informasi hasil dari monitoring keadaan perangkat dan lingkungan sekitar. Pengujian yang dilakukan penelitian ini menggunakan teknik Blackbox untuk menguji secara fungsional.

\subsection{Tahap Perencanaan}

Perencanaan merupakan tahap awal dalam menentukan kegiatan yang akan tercapai tujuan yang diharapkan sehingga semua kegiatan dapat terarah dan selesai secara efisien. Dalam membangun alat Pengontrolan $\mathrm{pH}$ dan suhu air tawar ini menggunakan NodeMCU ini tentunya diperlukan perangkat keras sebagai kontrol input dan output serta perangkat lunak sebagai sarana peneliti untuk menuliskan program kedalam mikrokontroller.

\section{Kebutuhan Perangkat Keras}

Kebutuhan perangkat keras yang dibutuhkan dalam membangun alat Pengontrolan $\mathrm{pH}$ air tawar menggunakan NodeMCU ini meliputi mikrokontroller dan komponen-komponen penunjangnya. Adapun alatalat lain yang dipakai untuk menunjang keberhasilan dalam membangun sistem ini berupa kabel, perangkat solder, dan lain-lain. Daftar kebutuhan perangkat keras perancangan alat Pengontrolan $\mathrm{pH}$ Air:
a. Mikrokontroller NodeMCU
b. Sensor pH Air (sebagai sensor kadar keasaman atau basa)
c. Sensor Suhu DS18B20 Waterproof (sebagai sensor pengukuran suhu air)
d. Pompa Air Dc 5v (sebagai pompa air akuarium)
e. LCD 1602 (sebagai monitor suhu)
f. Kabel jumper 
Pengembangan Rekayasa dan Teknologi, Vol 16, No. 1, Juni 2020, pp 1-8

p-ISSN: 1410-9840 \& e-ISSN: 2580-8850

http://journals.usm.ac.id/index.php/jprt/index

\section{Kebutuhan Perangkat Lunak}

Perangkat lunak yang dibutuhkan dalam perancangan ini adalah aplikasi Android, dalam sistem ini penulis menggunakan aplikasi Blynk untuk mengontrol alat. Seperti yang sudah di ketahui Blynk adalah platform aplikasi Android untuk mengendalikan Arduino dan berbagai macam modul mikrokontroler lainnya.

Sedangkan perangkat lunak yang digunakan dalam pemprograman NodeMCU adalah Arduino IDE digunakan sebagai sarana untuk menuliskan kode program pada mikrokontroller NodeMCU. Komponen NodeMCU inilah nantinya yang akan menerima intruksi dari pengendali perintah pesan yang di kendalikan melalui aplikasi Android (Wicaksono, 2017). Dengan demikian rangkaian perangkat mikrokontroller dapat berfungsi sebagaimana mestinya.

\subsection{Tahap Perancangan Desain}

Pada tahap ini penulis akan menerangkan tentang perancangan diagram blok, flowchart diagram system, desain prototype, dan perencanaan perancangan alat.

\section{Perancangan Diagram Blok}

Diagram blok merupakan salah satu bagian terpenting dalam perancangan, karena dari diagram blok dapat diketahui dalam Gambar 3 sebagai prinsip kerja keseluruhan rangkaian.



Gambar 3. Diagram Blok

Cara kerja Diagram Blok Sistem Pengontrolan pH Air pada Gambar 3 adalah smartphone Android berfungsi untuk memberikan perintah melalui perintah suara dan mengolahnya menjadi perintah untuk NodeMCU yang kemudian dikirim melalui perantara koneksi Wifi. NodeMCU berfungsi sebagai pengolah data masukan dan keluaran serta menjadi penghubung antara Android dengan relay [6].

Sedangkan Relay pemicu untuk menjadi ON ketika sesuai situasi / kondisi tertentu, dan memiliki sensor atau rangkaian timer (memanfaatkan 'time delay'). Baterai untuk power supply (pengaktifan relay), pompa air ke relay berguna secara otomatis air akan diganti, sensor ph air untuk mengukur tingkat keasaman dan basa. Kemudian sensor suhu untuk membaca suhu dengan ketelitian 9 hingga 12-bit, rentang $-55^{\circ} \mathrm{C}$ hingga $125^{\circ} \mathrm{C}$ dan LCD $16 \times 2$ sebagai monitoring kondisi ruangan sesuai dengan deteksi sensor $\mathrm{pH}$ Air dan sensor suhu.

\section{Flowchart Desain Sistem}

Flowchart (diagram alir) dapat digunakan sebagai alternatif untuk menyajikan algoritma, karena menggunakan simbol-simbol standar sehingga mudah untuk dipahami. Flowchart diperuntukan agar memudahkan melihat jalannya sistem yang akan di bangun secara garis besar, sehingga akan memudahkan dalam perancangan sistem itu sendiri. Dengan adanya flowchart pada Gambar 4 akan membantu gambaran output sebelum alat dan proses itu dirancang.

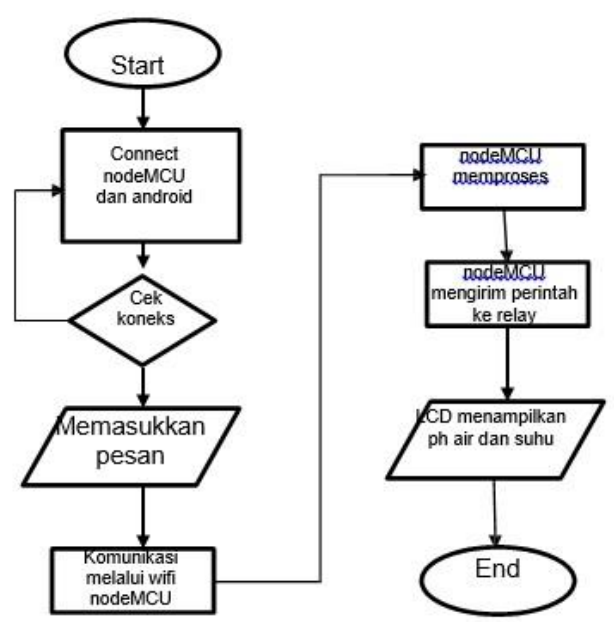

Gambar 4. Flowchart Sistem pengontrol pH Air dan Suhu Air

Start pada flowchart Gambar 4 menandakan proses awal yaitu koneksi ke Android dan NodeMCU. Pertama hubungkan smartphone dengan NodeMCU melalui tethering Wifi yang sesuai dengan program. Kemudian proses akan memeriksa koneksi Wifi. Jika sudah terhubung maka Android akan menampilkan notifikasi "device connected", jika belum maka proses akan diulang untuk menghubungkan Android dan NodeMCU kembali.

Apabila koneksi telah terhubung, maka Android dan NodeMCU akan dapat mulai mengucapkan kalimat perintah. Komunikasi melalui Wifi NodeMCU pada langkah ini berisi perintah pesan yang sudah diproses dan dikirim melalui komunikasi Wifi yang nantinya diterima oleh NodeMCU untuk melakukan operasi dan memberikan output lewat layar LCD 16x2. NodeMCU mengirim perintah ke relay yang kemudian mengeluarkan arus sesuai dengan proses yang diminta sehingga rangkaian LCD16x2 akan memberikan pesan $\mathrm{pH}$ air dan suhu air kemudian proses selesai. 
Pengembangan Rekayasa dan Teknologi, Vol 16, No. 1, Juni 2020, pp 1-8

p-ISSN: 1410-9840 \& e-ISSN: 2580-8850

http://journals.usm.ac.id/index.php/jprt/index

\section{Perancangan Desain Prototype}

Desain Prototype digunakan untuk memudahkan perancangan dan perakitan alat Pengontrolan $\mathrm{pH}$ Air dan suhu air di akuarium. Prototype dibuat sedemikan rupa agar praktis dan mudah dalam pengoperasian serta aman dalam penggunaannya.pada Gambar 5 diperlihatkan desain Prototype yang mencakup beberapa komponen seperti NodeMCU, Sensor pH air, Sensor Suhu, relay, LCD $16 \times 2$, baterai, dan pompa air.

Adapun desain prototype Alat Pengontrol $\mathrm{pH}$ Air dan suhu air pada air tawar menggunakan NodeMCU yang telah dirancang adalah sebagai berikut dalam Gambar 5.

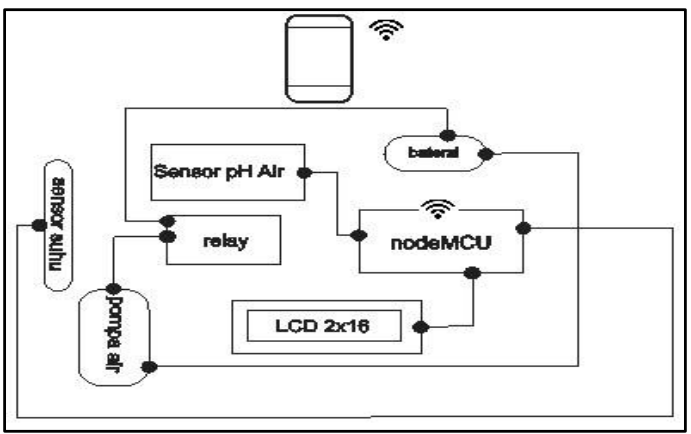

Gambar 5. Perancangan Desain Prototype

Smartphone pada Gambar 5 digunakan sebagai pengoperasi rangkaian menggunakan tethering Wifi sebagai komunikasi utama. NodeMCU, digunakan sebagai alat pengontrol dan perubah masukan perintah menjadi output ke relay. Sedangkan relay sebagai pemicu untuk menjadi menghidupkan rangkaian ketika kondisi air tidak stabil baik.

Rangkaian pemicu hidup apabila sensor telah mengirim data keadaan air baik $\mathrm{pH}$ maupun suhu yang sudah ditentukan di NodeMCU sehingga pompa air akan dapat secara otomatis menyedot air dan menggantinya dengan air dengan kondisi $\mathrm{pH}$ dan suhu yang lebih stabil. Sensor Suhu sendiri bekerja dengan tingkat ketelitian 9 bit hingga 12 bit dengan rentang $55^{\circ} \mathrm{C}$ hingga $125^{\circ} \mathrm{C}$ sedangkan Sensor Kejernihan Air

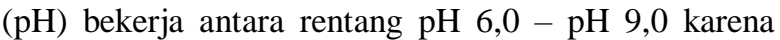
sensor ini mengukur tingkat keasam basaan air pula. Seluruh rangkaian pada Gambar 5 hidup karena aliran listrik dari baterai $9 \mathrm{~V}$ untuk power supply (pengaktifan relay).

\section{Perencanaan Perancangan Alat}

Berikut adalah gambar perencanaan alat yang diletakkan pada sebuah papan sebagai dudukan komponen yang terdapat dalam Gambar 6.

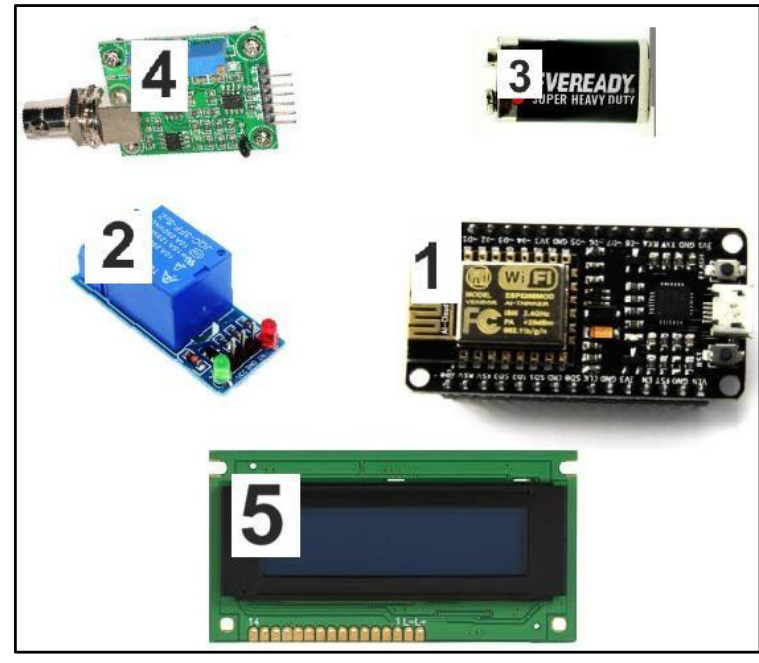

Gambar 6. Perencanaan Perancangan Alat

Keterangan Gambar 6 :

1. NodeMCU

2. Relay

3. Baterai

4. Sensor $\mathrm{pH}$ air

5. Lcd $16 \times 2$

Setelah mengetahui seluruh perencanaan dan perancangan dalam penelitian ini, maka skema pin NodeMCU dan keseluruhan Prototype dapat digambarkan sistem dapat berjalan sesuai program yang dibangun. Berikut adalah Gambar 7 skema keseluruhan rangkaian :

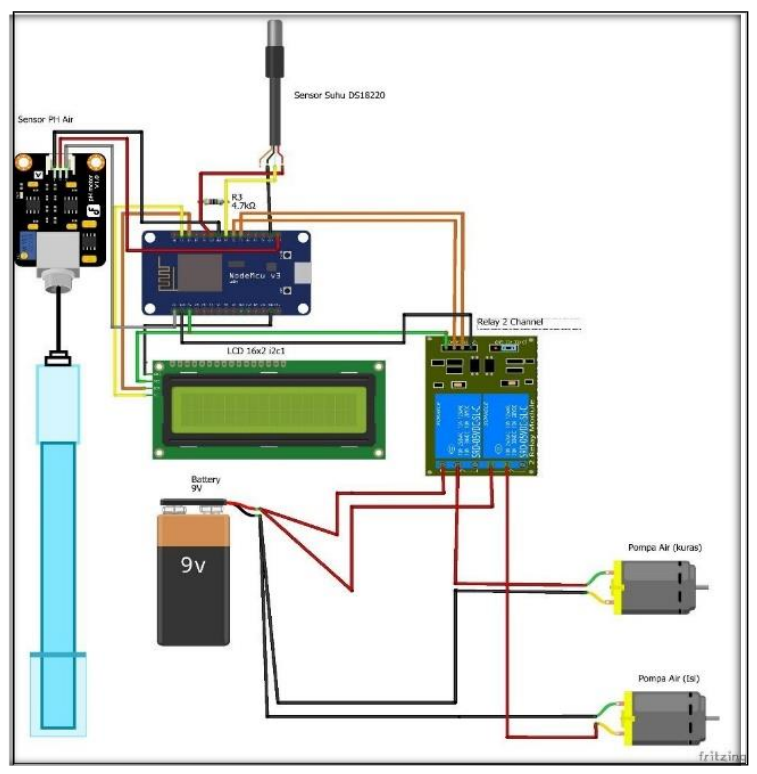

Gambar 7. Skema Keseluruhan Rangkaian 
Pengembangan Rekayasa dan Teknologi, Vol 16, No. 1, Juni 2020, pp 1-8

p-ISSN: 1410-9840 \& e-ISSN: 2580-8850

http://journals.usm.ac.id/index.php/jprt/index

\section{Tahap Perancangan Perangkat Lunak}

Perancangan perangkat lunak dilakukan untuk menyiapkan kebutuhan software yang digunakan penulis sebagai sarana upload kode program pada mikrokontroler. Perancangan perangkat lunak yang dibahas adalah pemasangan aplikasi android menggunakan aplikasi Blynk sebagai aplikasi pengontrol pada smartphone yang dapat diunduh pada Appstore ataupun Playstore secara gratis dan software Arduino IDE. Perencanaan menggunakan apliksai Blynk ini terdapat beberapa fitur yang dapat digunakan sesuai fungsi dan program yang akan dibuat. Adapun perencanaan antarmuka aplikasi adalah sebagai berikut dalam Gambar 8 .

\section{HASIL DAN PEMBAHASAN}

\subsection{Penelitian Terdahulu}

Berikut Tabel 1 adalah berbagai penelitian tentang monitoring suhu dan kelembaban yang telah dilakukan sebelumnya sebagai pedoman pengembangan teknologi pada penelitian ini.

Tabel 1. Penelitian Terdahulu

\begin{tabular}{lcrl}
\hline & Judul Penelitian & Hasil \\
\hline Rancang & Bangun Sistem Pendeteksi & Menggunakan sensor pH dan LDR dapat dibuat alat \\
Kualitas & Air Menggunakan Metode pengontrol kualitas air dengan memenuhi 2 dari 3 syarat \\
Fuzzy Logic [7] & kualitas air yang layak di konsumsi oleh masyarakat. \\
& & Keakurasian pada sensor pH mencapai lebih dari 80\% \\
\hline
\end{tabular}

Pengukur Tingkat Kekeruhan Keasaman Menentukan kualitas air dari parameter kekeruhan, Dan Suhu Air Menggunakan keasaman, dan suhu air dengan menggunakan smartphone Mikrokontroler Atmega328p Berbasis bersistem Android sebagai penampil data yang dihubungkan Android [8] ke mikrokontroler melalui koneksi bluetooth.

Rancang Bangun Sistem Kontrol pH Air Perangkat ini dapat mengontrol parameter pH air pada pada Palka Ikan Muatan Hidup palka ikan muatan hidup dengan menggunakan sensor Menggunakan Mikrokontroler dan $\mathrm{pH}$ melalui mikrokontroler Arduino Mega 2560 sebagai LabVIEW [9] perangkat pengolah data dan menampilkan proses pengolahan data pada perangkat lunak LabVIEW, sehingga sistem kontrol bekerja lebih optimal.

Beberapa penelitian dalam Tabel 1 membahas mengenai tingkat kejernihan dan suhu air dengan berbagai macam alat dan fitur dengan segala kebutuhan seperti untuk air minum dan kualitas air pada ikan Palka. Pada penelitian ini akan menggunakan NodeMCU, sensor $\mathrm{pH}$, sensor suhu, dan pompa ganda sebagai motor untuk monitoring kejernihan $(\mathrm{pH})$ dan suhu air untuk budidaya ikan terutama pada ikan hias.

\subsection{Arduino IDE (Integrated Development Environment)}

Dalam membangun suatu sistem dengan mikrokontroler NodeMCU diperlukan suatu aplikasi bernama Arduino IDE yang berfungsi untuk memberikan perintah atau coding untuk mikrokontroler NodeMCU v3. Berikut Gambar 9 adalah aplikasi Arduino ide yang berisikan coding yang akan mengkonfigurasi mikrokontroler NodeMCU v3. 
Pengembangan Rekayasa dan Teknologi, Vol 16, No. 1, Juni 2020, pp 1-8

p-ISSN: 1410-9840 \& e-ISSN: 2580-8850

http://journals.usm.ac.id/index.php/jprt/index



Gambar 9. Penulisan Program

\subsection{Blynk}

Blynk adalah aplikasi smartphone yang dapat digunakan untuk membuat perintah, tampilan, dan button setting penampil data yang diterima dari NodeMCU [10]. Langkah pertama untuk menggunakan Blynk adalah proses regristrasi. Proses regristrasi dapat dilakukan melalui Email atau via Facebook. Dalam penggunaannya Blynk memiliki beberapa tahap yaitu tahap pemilihan perangkat device, widget box, dan setting button..

Pada tahap pemilihan perangkat akan ada beberapa pilihan seperti memilih perangkat dan memilih koneksi perangkat, pada penelitian ini penulis menggunakan nama projek aquarium yang device ESP8266 serta Wifi sebagai media koneksi. Hasil dari tahap ini terdapat pada Gambar 10 berikut.

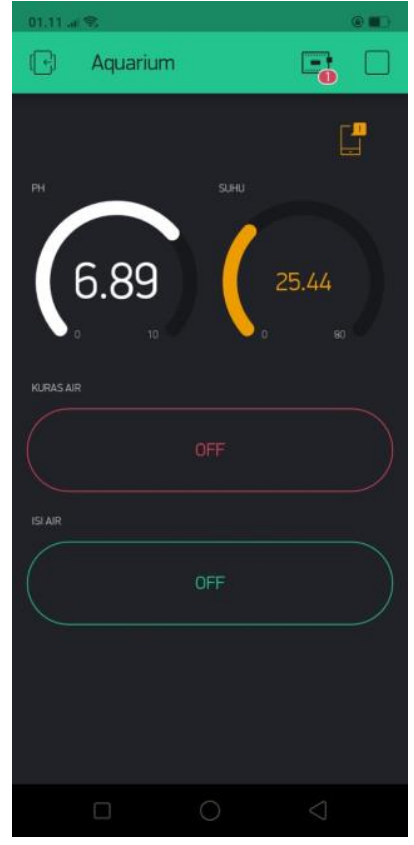

Gambar 10. Aplikasi IoT Kontrol pH dan Suhu pada Air Tawar

\subsection{Perakitan Perangkat Keras}

Pada tahap perakitan perangkat keras ini terdiri dari NodeMCU, LCD 16x2, relay, sensor $\mathrm{pH}$ air, sensor suhu, dan pompa air. Bagian - bagian dari hardware satu sama lain harus berhubungan dan bekerja sama secara harmonis atau berintegrasi sesuai dengan kebutuhan alat dan tujuan pembuatan pengontrol $\mathrm{pH}$ Air menggunakan internet.

Dari beberapa rangkaian modul di atas maka selanjutnya akan dirangkai menjadi satu yang membentuk sebuah alat yang saling terintegrasi seperti yang terdapat dalam Gambar 11 dan Gambar 12.

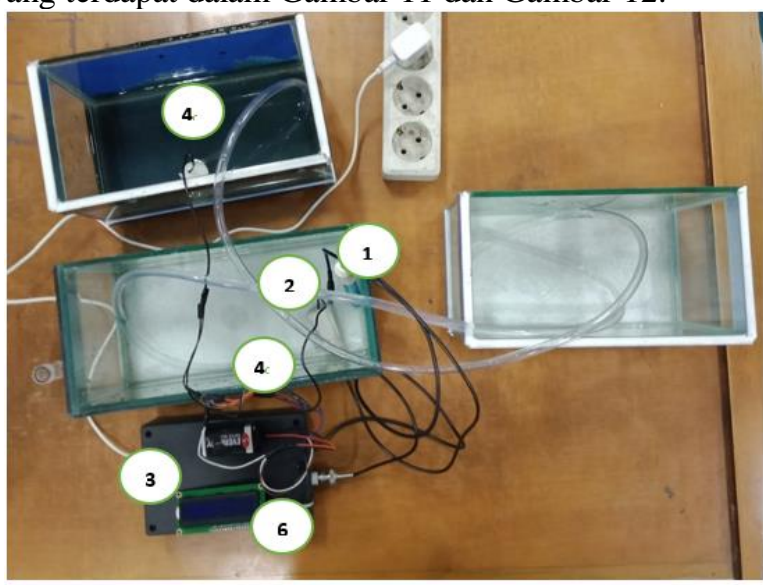

Gambar 11. Rangkaian Keseluruhan Prototype 
Pengembangan Rekayasa dan Teknologi, Vol 16, No. 1, Juni 2020, pp 1-8

p-ISSN: 1410-9840 \& e-ISSN: 2580-8850

http://journals.usm.ac.id/index.php/jprt/index



Gambar 12. Rangkaian di Dalam Kotak

Keterangan :

1. Sensor $\mathrm{pH}$ Air

2. Sensor Suhu

3. Baterai 9V

4. Pompa Air

5. NodeMCU

6. LCD $16 \times 2$

\subsection{Pengujian Blacbox}

Pengujian Blackbox dilakukan untuk mengetahui apakah alat bekerja dengan normal, seperti menguji fungsi yang sesuai atau bekerja, menguji fitur alat, serta menguji respon alat. Tabel 2 berikut adalah hasil Pengujian Blackbox

Tabel 2. Hasil Pengujian Blackbox

\begin{tabular}{llll}
\hline $\begin{array}{l}\text { Input/penguj } \\
\text { ian }\end{array}$ & Fungsi & Output & Hasil Uji \\
\hline $\begin{array}{l}\text { Running } \\
\text { Aplikasi }\end{array}$ & $\begin{array}{l}\text { Menjalankan } \\
\text { Aplikasi }\end{array}$ & $\begin{array}{l}\text { Menu Utama } \\
\text { Aplikasi }\end{array}$ & Berhasil \\
\hline $\begin{array}{l}\text { Memilih } \\
\text { koneksi Wifi }\end{array}$ & $\begin{array}{l}\text { Menghubungkan } \\
\text { antara perangkat } \\
\text { smartphone dan }\end{array}$ & Wifi & Berhasil \\
& NodeMCU & & \\
& Menampilkan pH pH air dan & Berhasil \\
LCD 16x2 & air dan suhu & suhu tampil & \\
\hline $\begin{array}{l}\text { Button } \\
\text { perintah }\end{array}$ & $\begin{array}{l}\text { Media pembaca } \\
\text { dan penerjemah }\end{array}$ & $\begin{array}{l}\text { Menjalankan } \\
\text { perintah yang }\end{array}$ & Berhasil \\
aplikasi & yang dimasukan terbaca oleh & \\
oleh user. & aplikasi & \\
\hline
\end{tabular}

Pengujian Blackbox yang telah dilakukan menunjukkan bahwa alat telah dibangun sudah memenuhi persyaratan fungsional yang dapat dilihat dari hasil pengujian yang menunjukkan keberhasilan dari beberapa kali percobaan.

\subsection{Pengujian Kuesioner}

Pengujian kuesioner dilakukan secara objektif dimana diuji secara langsung kepada pengguna yaitu pengusaha ikan di Pasar Johar Semarang sejumlah 10 orang untuk melihat penilaian ataupun respon pengguna terhadap alat yang telah dibangun. Penilaian dilakukan dengan cara membagikan kuesioner mengenai cara kerja alat serta kepuasan pengguna terhadap alat. Hasil pengujian dengan kuesioner membuktikan bahwa IoT yang dibangun dapat digunakan kedepannya untuk membantu pengusaha ikan terutama ikan hias untuk menurunkan tingkat kematian ikan karena $\mathrm{pH}$ air dan suhu air yang tidak seimbang. Hasil pengujian kuesionner secara keseluruhan terdapat pada Gambar 13 sebagai berikut.

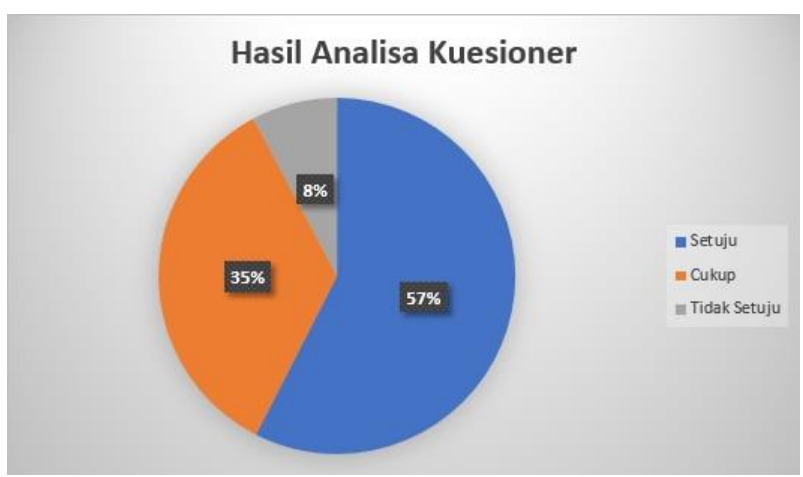

Gambar 13. Hasil Analisa Kuesioner

Dari hasil analisa kuesioner pada Gambar 13 didapatkan bahwa $57 \%$ pengguna sistem setuju dengan hasil penelitian ini dapat membantu menurunkan tingkat kematian ikan karena $\mathrm{pH}$ air dan suhu air yang tidak seimbang. Sedangkan untuk tingkat kepuasan sebanyak $35 \%$ kebanyakan diisi oleh pengusaha ikan yang berumur kira-kira diatas 40 tahun yang baru belajar menggunakan teknologi ini dan $8 \%$ tidak setuju karena lebih suka menggunakan cara konvensional dalam memelihara ikan-ikan dagangan mereka.

\section{SIMPULAN}

Dari hasil analisa dan implementasi diperoleh melalui pengujian dapat disimpulkan sebagai bahwa sistem pengontrolan $\mathrm{pH}$ dan suhu air pada air tawar secara otomatis dapat dirancang dengan menggunakan NodeMCU dan sensor analog $\mathrm{pH}$ Air. Perangkat ini dapat diatur dengan nilai $\mathrm{pH}$ minimum dan maksimumnya sesuai dengan range $\mathrm{pH}$ yang dibutuhkan sehingga $\mathrm{pH}$ pada air tawar tetap terkontrol dan stabil pada nilai yang diinginkan untuk keperluan budidaya ikan. Dengan dioperasikan dengan smartphone Android yang mayoritas banyak penggunanya dan aplikasi yang menarik serta mudah dalam penggunaan sehari hari serta didukung dengan peralatan yang mudah didapat terbukti dengan hasil kuesioner kepuasan pengguna mencapai $57 \%$ setuju sistem ini dapat membantu menurunkan tingkat kematian ikan karena $\mathrm{pH}$ air dan suhu air yang tidak seimbang.

Saran yang dapat diberikan untuk pengembangan kearah monitoring kadar oksigen terlarut DO (dissolved oxygen) sehingga menambah baik kualitas air tawar yang dipantau. 
Pengembangan Rekayasa dan Teknologi, Vol 16, No. 1, Juni 2020, pp 1-8

p-ISSN: 1410-9840 \& e-ISSN: 2580-8850

http://journals.usm.ac.id/index.php/iprt/index

\section{DAFTAR PUSTAKA}

[1] F. Astria, M. Subito, and D. W. Nugraha, "RANCANG BANGUN ALAT UKUR PH DAN SUHU BERBASIS SHORT MESSAGE SERVICE (SMS) GATEWAY," J. Metr., vol. 1, no. 1, pp. 47-55, 2014.

[2] E. Kusrini, "Budidaya Ikan Hias Sebagai Pendukung Pembangunan Nasional Perikanan di Indonesia," Media Akuakultur, vol. 5, no. 2, pp. 109-114, 2010.

[3] A. Qalit, Fardian, and A. Rahman, "Rancang Bangun Prototipe Pemantauan Kadar $\mathrm{pH}$ dan Kontrol Suhu Serta Pemberian Pakan Otomatis pada Budidaya Ikan Lele Sangkuriang Berbasis IoT,” KITEKTRO, vol. 2, no. 3, pp. 8-15, 2017.

[4] C. Solamo and M. Rowena, Software Engineering, 1.2. Java Education \& Development Initiative (JEDI), 2006.

[5] M. F. Wicaksono, "IMPLEMENTASI MODUL WIFI NODEMCU ESP8266 UNTUK SMART HOME," J. Tek. Komput. Unikom-Komputika, vol. 6, no. 1, pp. 9-14, 2017.

[6] M. Saleh and M. Haryanti, "RANCANG BANGUN SISTEM KEAMANAN RUMAH
MENGGUNAKAN RELAY,” J. Teknol. Elektro, Univ. Mercu Buana, vol. 8, no. 3, pp. 181-186, 2017.

[7] M. Abdullah, E. Susanto, and I. Wibawa, "RANCANG BANGUN SISTEM PENDETEKSI KUALITAS AIR MENGGUNAKAN METODE FUZZY LOGIC UNIVERSITAS TELKOM ( DESIGN AND IMPLEMENTATION OF WATER QUALITY DETECTION SYSTEM WITH FUZZY LOGIC METHOD ) TELKOM UNIVERSITY," $e$ Proceeding Eng., vol. 3, no. 2, pp. 1321-1326, 2016.

[8] A. Prayoga, Y. Ramdhani, A. Mubarok, and S. Topiq, "Pengukur Tingkat Kekeruhan Keasaman Dan Suhu Air Menggunakan Mikrokontroler Atmega328p Berbasis Android," J. Inform., vol. 5, no. 2, pp. 248-254, 2018.

[9] T. Manalu, R. Pramana, E. Prayetno, and S. Nugraha, "Rancang Bangun Sistem Kontrol pH Air pada Palka Ikan Muatan Hidup menggunakan Mikrokontroler dan LabVIEW," J. Sustain., vol. 07, no. 02, pp. 53-63, 2018.

[10] Blynk, "The Most Populer," 2017. [Online]. Available: https://blynk.io/. 